\title{
AUTOMATED SOFTWARE DISTRIBUTION
}

\author{
J J Strasheim Pr Eng * \\ Department of Industrial and Systems Engineering \\ - University of Pretoria \\ Pretoria, South Africa \\ P S Kruger Pr Eng \\ Department of Industrial and Systems Engineering \\ University of Pretoria \\ Pretoria, South Africa
}

\section{ABSTRACT}

Automated distribution of computer software via electronic means in large corporate networks is growing in popularity. The relative importance of personal computer software, in financial and logistical terms, is described and the developing need for automated software distribution explained. An actual comparitive example of alternative software distribution strategies is presented and discussed proving the viability of Electronic Software Distribution.

\section{OPSOMMING}

Geoutomatiseerde verspreiding van rekenaarprogrammatuur met behulp van elektroniese metodes in groot korporatiewe netwerke, is toenemend populêr. Die relatiewe belangrikheid van persoonlike rekenaarprogrammatuur in finansiële en logistieke terme word bespreek en die groeiende behoefte na geoutomatiseerde programmatuurverspreiding verduidelik. 'n Werklike vergelykende voorbeeld van alternatiewe programmatuurverspreidingsstrategiëe word aangebied en bespreek wat die lewensvatbaarheid van Elektroniese Programmatuurverspreiding bewys.

* Johan Strasheim and Associates, Pretoria 


\section{BACKGROUND}

"Technology made large populations possible; large populations make technology indispensable"

\section{- JOSEPH WOOD KRUTCH}

In the quest for enhanced productivity companies have rapidly accelerated the wide scale adoption of computer based data and management information services. Despite the occasional failure, most companies have found some significant benefits from the improved information handling within their particular environment. As technology advance and users become more informed and computer literate, less paper should flow and desks should become smaller. All integration may soon be carried out on personal computers linked to the local and remote networks. Although there are some problems with the electronic delivery of information, the major stumbling blocks are ones of cost-benefit and user education.

Although technology may change radically from what is currently state of the art, the basic principles of information management will stay the same. What has become more important as the information horizons expand, is that data as well as software have become perishable, time dependant commodities, and this is where the greatest challenges lie for data processing professionals in the immediate future. For product prices and foreign exchange rates, minutes are important, while for most data such as sales history and government statistics, weekly of even monthly cycles are adequate. Software levels have an ad-hoc time dependency. When legislation changes, such as the system changing from general sales tax to one of value added tax, application software changes have to be in place and implemented at a very specific point in time. Whatever delivery options are chosen must reflect this perishability, so that the user does not end up paying for an hourly update that is only significant on a weekly basis.

The enormous increase over recent years in the number of Personal Computers and other distributed information systems have resulted in a complete new area of management concern in the Information Technology (IT) industry. Keeping remote systems updated and performing remote support have become two of the most important and expensive but manageable items in today's Information Technology industry, if approached correctly. It is not receiving the degree of attention from management that it should, like so many similar issues. 
Worldwide expenditures for personal computer software are now greater than the amount spent on either minicomputer or mainframe computer software [3], and the disparity will increase in the years ahead. Mainframe software has always been fairly expensive but the effect of purchase price is typically applied across a large number of users. Personal computer software on the other hand, is typically cheaper but is, with a few exceptions, all single user applications. This fragmented situation spawns a large number of new problems and asset management challenges for which new solutions are continually being sought.

The Gartner Group [3] in a report on software distribution states that in a typical US . organization with 2,000 personel computers, the capital cost of personal computer software is nearly $\$ 1,5$ million, and annual updates can often cost $\$ 200,000$ or more. If the organization is a typical one, it will spend nearly $\$ 30$ million over the next five years on personal computer software.

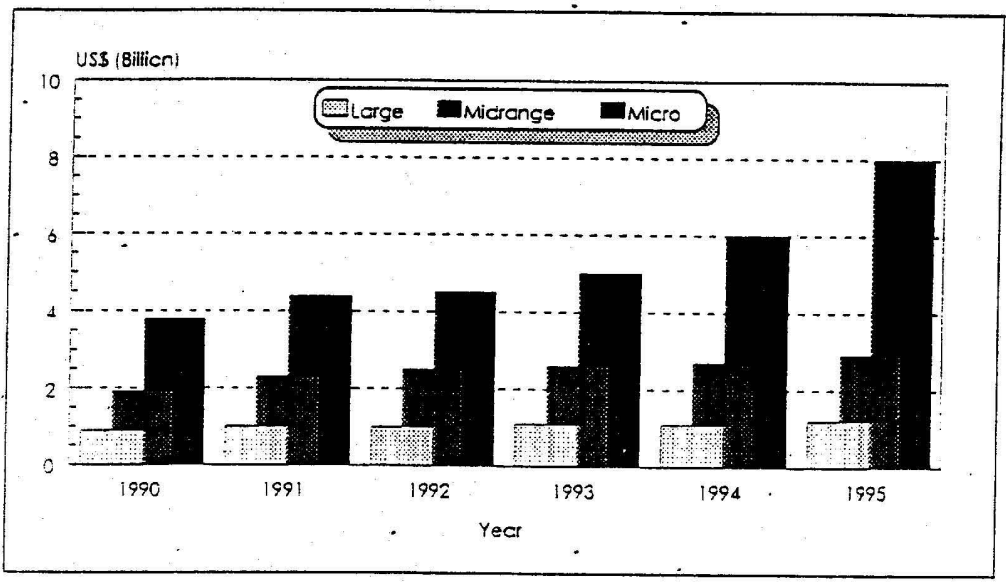

Figure 1. Worldwide Software Value by system (US\$ billion)

Coupled with indirect cost, such as labour for support, installation and maintenance as well as growing in-house custom development, personal computer software represents a huge, recurring cost to any organization and must be managed as a portfolio to minimize cost and maximize return.

Considering that, in South Africa computer users typically face cost that are currently in the region of 3 to 4 times higher than the aforementioned due to an ever increasing $R / \$$ exchange rate, fairly substantial shipping cost because of its geographical position and significant

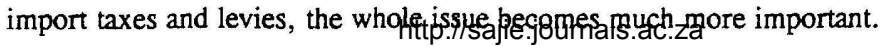




\section{THE REAL COST OF PERSONAL COMPUTER SOFTWARE}

To put the scenario in perspective, one has to describe the total cost involved in installing and maintaining distributed system software. The 'distributed system' will for the 'sake of simplicity be referred to as a personal computer (PC) in the sense of a generic 'small' computer system, although it would not actually be correct. All distributed systems definitely are not PC's.

The real cost of PC software, license and upgrade fees represent only 24 percent of the fiveyear life-cycle cost of a typical desktop software suite. The indirect cost to select, distribute, install, learn, train and support the software represents by far the biggest investment. Further, direct cost is a one-time event, whereas the bulk of the cost are ongoing, creating a cumulative cost that can become prohibitively large. Many organizations have been frozen at ancient and mixed release levels of operating system and application system software versions simply because of the effort and implicit cost of change. This distribution of cost is depicted in Figure 2.

Although the costs associated with the initial purchase and ongoing support of a software programme is quite substantial and highly visible, users typically will spend more on procuring and supporting application updates. Looking for ways to streamline the selection, administration, distribution, installation and support of updates have a major impact on the overall PC software life-cycle cost. Most companies concentrate on minimizing PC software cost by negotiating with suppliers to minimize initial cost via volume discounts and site licenses. In the larger scope of things, the effect of this is minor when compared to the overwhelming indirect cost of PC software ownership.

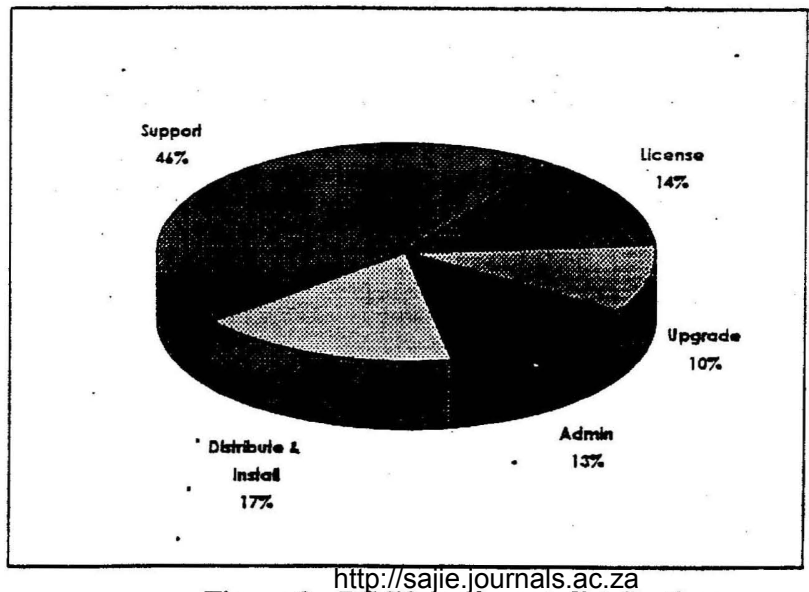

Figure 2. PC life cycle cost distribution 
The real challenge emerges as companies are producing software application in the client/server model. The traditional methods of manually distributing software will be inadequate for these systems. The frequency of updates will also increase substantially.

The issues of configuration control and software synchronization are critical factors in distributed systems. One of the most costly components of the process is installation of software, usually by the end user, on each machine. If each installation takes one hour, a 2,000-machine upgrade will involve a full man year of productive effort, assuming that there are no problems where high powered skills and expertise may be required.

One of the operation realities of distributed systems is the need to maintain currency of data and software on literally hundreds to thousands of computers in geographically removed locations. Electronic software and data distribution is still somewhat of a new concept, but will impact on the distributed computing market place enormously and is currently gaining ground. It reduces a nearly unmanageable labour load and enables a new type of distributed computing. Client/server computing on a broad scale would be impractical without an ability to automatically distribute and install software on every computing platform in the company or group.

\section{ELECTRONIC SOFTWARE DISTRIBUTION SYSTEMS}

While an Electronic Software Distribution System (ESDS) may share some of the underlying technology of other data communications based systems such as Electronic Mail and File Transfer, the ESDS functional specifications are different. An ESD is driven by Information Systems requirements rather than by end-user requirements.

Although it is not the intention to fully describe the ESDS specifications, some are worth mentioning at this point. Such systems should span all kinds of alternate technology platforms such as DOS, LANs, CTOS, Windows, Apple Mac, OS/2, UNIX and Mainframes such as IBM's MVS/VTAM systems and Unisys A-series systems, in other words the operating systems and hardware platforms that exist in the corporate environments. It should also have data compression facilities and comprehensive file transfer facilities with auditing, security and unattended operation amongst others. Such systems are slowly entering the market as the aforementioned needs develop and the Information Technology industry starts to realize what it really costs to distribute software. 
The natural answer is to apply technology to the problem. Not only does an automated approach reduce hard distribution costs, but potential benefits in better support and the ability to change and adapt more quickly can also be measured and realized. It is interesting to note that many independent software vendors currently do not allow electronic distribution of software in the standard shrink-wrapped license agreement.

Even if ESDS is limited to in-house software and some shrink-wrapped updates, the value of these products are still high. An ESDS can be a platform for a wide range of helpful and also mandatory system management functions such as configuration management, remote operation, remote support and security control.

In summary, the major benefits of Electronic Software Distribution are:

- $\quad$ Reduced cost of software changes.

- $\quad$ Reduced need for site visits.

- Increased service quality.

- Automated installations.

- Synchronised software changes.

- Meeting legislative change requirements. .

- Control of software resources.

- Maintained version control.

\section{THE COST OF SOFTWARE DISTRIBUTION}

It is no secret that software distribution is a very costly function, primarily due to the logistical and technical complexity of such an exercise - especially when dealing with a large distributed network. Such updates are typically performed in one of three ways:

- SWAT Teams. Teams of support personnel and user staff would physically travel all over the place and install the new software from diskette or tape.

- Mailing Distribution Diskettes. Diskettes containing the new software release with installation instructions is mailed to all sites for installation. Users would be assisted over the telephone to overcome installation problems.

- Electronic Śftware Distribution. Software updates are electronically downloaded to the branches for automatic installation. 
There are many ways of evaluating the financial feasibility of Electronic Software Distribution applications and these nearly always prove overwhelming economic feasibility over a period of use longer than two years.

What is clear, is that electronic software distribution is the best long term solution to the problem, both in financial terms and otherwise. Electronic Software Distribution Systems are definitely the way for the future despite the initial investment cost involved. Figure 3 depicts the situation graphically for a typical scenario [3].

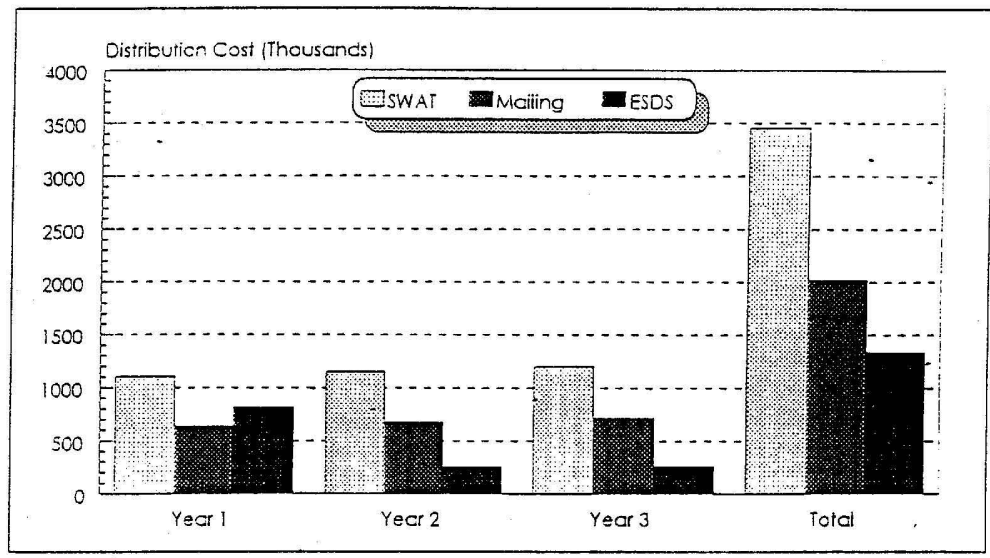

Figure 3 : Comparative Cost of Software Distribution Alternatives

\section{- SUMMARY}

There is no question that the complexity of administration of work groups remain a source of frustration that will start to impact the cost and feasibility of deploying client-server solutions. Where a software update on a centralised mainframe system in the 'old days' was a fairly simple procedure, the distributed architecture of today's networks left functions such as software distribution woefully lacking.

The initial software distribution products that have been released to the commercial market do have certain functionality but there is certainly great scope for further and deeper research into the subject to enhance the contribution that such products can make to efficiency of operations on the user level. http://sajie.journals.ac.za 


\section{- REFERENCES}

[1] Electronic Information Delivery : Proceedings of the conference held in London, October 1987. Online Publications 1987.

[2] Gartner Group, Inc, "PC Software : The cost cow of the 90's ?", PERSONAL COMPUTING, June 24, 1991.

[3] Gartner Group, Inc, "Software Distribution : Getting the code to the node", Unpublished paper at the tenth annual Personal Computing Conference, April 1992. 